\title{
AUTONOMOUS VEHICLES AND THE LAW: TECHNOLOGY, ALGORITHMS AND ETHICS. LIM, Y. H.
}

by

\section{VERONIKA ŽOLNERČÍKOVÁ*}

Lim, Y. H. (2018) Autonomous Vehicles and the Law: Technology, Algorithms and Ethics. Cheltenham: Edward Elgar Publishing, 147 p.

The ninth instalment of Elgar law, technology and society series, Autonomous Vehicles and the Law: Technology, Algorithms and Ethics, is focused on autonomous vehicles, new technology on the rise that stirs discussions in various fields of law, such as data protection, tort liability, traffic laws, cybersecurity and ethics.

Elgar law, technology and society series aims to provide an interdisciplinary forum for debate concerning legal and social implications of digital technology. ${ }^{1} \quad$ The interdisciplinary approach of the reviewed book is allowed by the author's double degrees in Computer Science and in Law. ${ }^{2}$

Autonomous Vehicles and the Law: Technology, Algorithms and Ethics represents a concise contribution to the debate on artificial intelligence and law, explaining the underlining technology on an example of self-driving vehicles. The book provides a profound background on the self-driving technology with the purpose to explain it in an understandable manner to lawyers.

zolnercv@law.muni.cz, Ph.D. candidate at the Institute of Law and Technology at Masaryk University, Brno, The Czech Republic.

1 Elgar law, technology and society series. [online] Available from: https://www.e-elgar.com/ shop/books?book_series=Elgar\%20Law,\%20Technology\%20and\%20Society\%20series [Accessed 20 August 2019].

2 See p. viii of the book. 
As stated in the book's Preface, the author's intent was to clarify exaggerations and misconceptions about autonomous vehicles. ${ }^{3}$ According to her, those first appeared in the popular press but spread to the academic literature as well. As a remedy she proposes firstly to bring about the general understanding of the issue and subsequently to formulate new ideas on the regulation concerning autonomous vehicles in the publication. ${ }^{4}$

The main hypothesis of this book, as stated in the Introduction, is that autonomous vehicles are not as safe as manufacturers tend to claim and that much of the legal literature is based on misconceptions ${ }^{5}$. The most important of which is that autonomous vehicles are based on a brand-new technology, when in reality functions of self-driving vehicles are set within the well-known framework of computer programs. ${ }^{6}$ Therefore, they might be not the solution we are looking for, since some of these features are already present in conventional vehicles and their functions are limited. ${ }^{7}$

After the assessment of the state of the art of the technology, the author confirms her hypothesis that the technology is not yet ready for full operation and neither statistics nor science proves it would be safer than current road traffic system. ${ }^{8}$

Furthermore, the author considers the public focus on autonomous mobility to be a hype. ${ }^{9}$ Therefore, her goal is to clarify the inherent limitations of the technology putting to use her knowledge on the subject. ${ }^{10}$ Subsequently, current legal standards are assessed, and new regulations and ethical considerations are discussed. ${ }^{11}$ The first goal is achieved by a thorough theoretical explanation of the technology. The second goal, the assessment from the legal standpoint, is more of a collection of the author's own ideas on the matter.

The book can be, in the reviewer's opinion, divided into two parts based on the prevalent content of its chapters and the method used. Chapters 2 to 4 and chapter 7 focus solely on the technical aspects of autonomous vehicles,

\footnotetext{
See $p$. ix of the book.

Ibid.

See pp. 1-3 and pp. 136-137 of the book.

See p. 2 of the book.

Ibid.

8 See p. 133 of the book.

9 See p. ix of the book.

${ }^{10}$ See pp. 1-3 of the book.

11 See p. 3 of the book.
} 
mainly on available data concerning accidents of autonomous vehicles. ${ }^{12}$ These are more of a descriptive nature. On the contrary, chapter 5 and 6 cover legal and ethical issues and reflect author's own thoughts on the matter.

Concerning the legal and ethical part, the book provides a good summary of current regulatory approaches in the chapter The road less travelled for regulators ${ }^{13}$ and a detailed analysis of ethical guidelines presented by an Ethics Committee set by the German Ministry of Transport and Digital Infrastructure in chapter Ethical responsibilities and autonomous vehicles $^{14}$. What do these chapters bring to legal academic literature on the matter?

The road less travelled tackles the problem of verifiable standards of care. It focuses mostly on the software of the vehicle, allowing us to explore this specific issue in detail. Additionally, the chapter Ethical responsibilities and autonomous vehicles offers an in-depth analysis of the German ethical guidelines, aiming to go beyond the trolley problem. ${ }^{15}$ The enforceability of proposed ethics guidelines is measured against the real amount of control the programmer can have over different types of programming of autonomous vehicles. Both chapters are welcomed additions to academic literature on the subject offering a specialized view on the matter.

That said, the framing of the legal and ethical part is very confusing. Whereas during the technical chapters of the book the focus lies on the United Kingdom, the United States of America and Australia, their regulations and case law, chapter 5, The road less travelled for regulators, suddenly includes only US laws and then EU Product Defect Directive and Road Traffic Act in Germany. The next chapter focuses only on Ethical guidelines in Germany. The reason behind focusing on these specific documents is not explained in the book. Nor is mentioned the existence of other relevant regulations, such as the regulation in Netherlands, which is on top of the Autonomous Vehicles Readiness Index ${ }^{16}$ and surely worth mentioning. As a result, a non-informed reader might get the idea that such

12 Worldwide accidents of Tesla Model S, Tesla Model X and Uber taking place from 2016 to 2018 are included.

13 See pp. 99-116 of the book.

${ }^{14}$ See pp. 117-132 of the book.

15 See pp. 117-118 of the book.

16 KPMG. (2019) 2019 Autonomous Vehicles Readiness Index. [online] Available from: https://assets.kpmg/content/dam/kpmg/xx/pdf/2019/02/2019-autonomous-vehiclesreadiness-index.pdf [Accessed 20 August 2019]. 
regulation is unavailable. However, a regulation is effective or is in the approval proceedings also in Canada, China, Japan, Norway, United Arab Emirates, Singapore and others. ${ }^{17}$

Furthermore, the manuscript is based on literature published before 26 May 2018. ${ }^{18}$ It also reflects accidents occurring during the year $2018 .{ }^{19}$ But when talking about the EU Product Defect laws, only Guidelines on Regulating Robotics ${ }^{20}$ from 2014 are mentioned. On the other hand, the Report with Recommendations to the Commission on Civil Law Rules on Robotics ${ }^{21}$ from July 2017 is omitted as well as the document Liability for Emerging Digital Technologies ${ }^{22}$ from April 2018. Both are relevant for autonomous mobility and the debate around liability for product defects.

The choices of the author to include some documents and not others for the assessment in chapter 5 might be intentional. However, a clear methodology regarding the selection of mentioned documents is missing. That disables the researchers who would like to be able to follow author's train of thoughts from doing so.

Chapter 3 called Verifiable standards of care is the most crucial chapter of the book. It is beneficial to everyone who is interested in the topic, whether a legal professional or a member of the general public. It is very well written, and it provides an up-to-date summary of road traffic accidents involving autonomous vehicles in an understandable manner, yet with more expertise than we are used to from newspaper articles.

Even though this chapter does not primarily address the issue of allocation of liability, it serves as a foundation for further debate about the matter. It differentiates among the malfunctions of sensors, the car as a whole and the driving software. The author states in every case who is (in her opinion) the one in breach with standard of care. The standard of care, she is using, is based on the legislation in the UK, US and Australia.

17 Ibid.

18 See p. ix of the book.

19 See pp. 99-116 of the book.

20 Palmerini, M. (2014) Guidelines on Regulating Robotics. [online] Available from: http://www. robolaw.eu/index.htm [Accessed 20 August 2019].

${ }^{21}$ European Parliament. (2017) Report with Recommendations to the Commission on Civil Law Rules on Robotics. [online] Available from: http://www.europarl.europa.eu/doceo/document/ A-8-2017-0005_EN.html [Accessed 20 August 2019].

22 European Commission. (2018) Liability for Emerging Digital Technologies. [online] Available from: https://eur-lex.europa.eu/legal-content/en/ALL/?uri=CELEX\%3A52018SC0137

[Accessed 20 August 2019]. 
The next chapter, Software: difficult to verify standards of care, specifically addresses the issue software in autonomous vehicles from the technical perspective. The author differentiates between so-called verifiable standards of care, which are applied to the physical components and the non-existent standards for software. These revolve around the technology that should be used for the development of autonomous software $^{23}$ as well as datasets ${ }^{24}$, from which it shall learn. This chapter is also a must-read to anyone who wants to further their knowledge of autonomous vehicles. It offers easily understandable explanations on different programming choices, differences between automatic and autonomous functions of software and issues with the burden of proof when it comes to software.

The overall problem of software regulation is well summarised at the beginning of the next chapter ${ }^{25}$ called The road less travelled for regulators. The knowledge gained on possible programming choices is useful in the chapter on ethics. Both chapters were discussed earlier in the review.

Overall, the book is beneficial to everyone interested in autonomous mobility and easily understandable for people with legal background. Benefits of the book lie especially in this thorough analysis of series of accidents of autonomous vehicles from 2016 to 2018, their causes and how they influenced the development of the field. All presented cases are followed with a summary on how this affects or should affect relevant regulation in the field. The author's unique perspective, as a lawyer and a computer scientist, allows her to stress the issues that are most challenging from a legal perspective.

The book aimed high - it attempted to clarify some common misconceptions both from a technical and legal standpoint. The reviewer is of the opinion that it did a great job doing so especially from the technical point of view. The shortcomings of the publication are mentioned above and affected only the parts on regulation and ethics. The only regrettable thing is that the concise format might have prevented the author to explain more about her choices or to argue more about certain issues.

23 See pp. 82-94 of the book.

24 See pp. 94-99 of the book.

25 See pp. 99-110 of the book. 
For those looking for complex information on autonomous vehicles, this book does not cover all. For example, it does not tackle some issues related to standards of care and product defect liability, such as interconnected road traffic systems or possible choices on how to mitigate damages with other legal tools than just liability. However, this is covered thoroughly in other literature, which can greatly complement the book by Lim. ${ }^{26}$ For a broader view on the topic of autonomous mobility, the book Autonomous driving by Maurer et al. ${ }^{27}$ can be also recommended by the reviewer.

What the book Autonomous Vehicles and the Law: Technology, Algorithms and Ethics does offers compared to other literature is a unique interdisciplinary perspective that will be invaluable to those who crave more information on the operation of autonomous technology, such as scholars or policy makers, and a pleasant read to others.

\section{LIST OF REFERENCES}

[1] Collingwood, L. (2017) Privacy Implications and Liability Issues of Autonomous Vehicles. Information \& Communications Technology Law, 26 (1).

[2] De Bruyne, J. and Tanghe, J. (2018) Liability for Damage Caused by Autonomous Vehicles: A Belgian Perspective. Journal of European Tort Law, 8 (3).

[3] Elgar law, technology and society series. [online] Available from: https://www.e-elgar.com/ shop/books?book_series=Elgar\%20Law,\%20Technology\%20and\%20Society\%20series

[Accessed 20 August 2019].

[4] European Commission. (2018) Liability for Emerging Digital Technologies. [online] Available from: https://eur-lex.europa.eu/legal-content/en/ALL/?uri=CELEX\%3A52018SC 0137 [Accessed 20 August 2019].

[5] European Parliament. (2017) Report with Recommendations to the Commission on Civil Law Rules on Robotics. [online] Available from: http://www.europarl.europa.eu/doceo/ document/A-8-2017-0005_EN.html [Accessed 20 August 2019].

${ }^{26}$ See Schellekens, M. (2015) Self-driving Cars and the Chilling Effect of Liability law. Computer Law E Security Review, 31 (4), pp. 506-517; Schellekens, M. (2018) No-fault Compensation Schemes for Self-driving Vehicles. Law, Innovation and Technology, 10 (2), pp. 314-333; Prakken, H. (2017) On the Problem of Making Autonomous Vehicles Conform to Traffic Law. Artificial Intelligence and Law, 25 (3), pp. 341-363; Prakken, H. (2017) On Making Autonomous Vehicles Respect Traffic Law: A Case Study for Dutch Law. Proceedings of the 16th edition of the International Conference on Artificial Intelligence and Law, pp. 241-244; De Bruyne, J. and Tanghe, J. (2018) Liability for Damage Caused by Autonomous Vehicles: A Belgian Perspective. Journal of European Tort Law, 8 (3), pp. 324-371; Collingwood, L. (2017) Privacy Implications and Liability Issues of Autonomous Vehicles. Information E Communications Technology Law, 26 (1), pp. 32-45.

27 Maurer, M. et al. (2016) Autonomous Driving: Technical, Legal and Social Aspects. Berlin: Springer Berlin Heidelberg. 
[6] KPMG. (2019) 2019 Autonomous Vehicles Readiness Index. [online] Available from: https://assets.kpmg/content/dam/kpmg/xx/pdf/2019/02/2019-autonomous-vehiclesreadiness-index.pdf [Accessed 20 August 2019].

[7] Maurer, M. et al. (2016) Autonomous Driving: Technical, Legal and Social Aspects. Berlin: Springer Berlin Heidelberg.

[8] Palmerini, M. (2014) Guidelines on Regulating Robotics. [online] Available from: http://www.robolaw.eu/index.htm [Accessed 20 August 2019].

[9] Prakken, H. (2017) On Making Autonomous Vehicles Respect Traffic Law: A Case Study for Dutch Law. Proceedings of the 16th edition of the International Conference on Artificial Intelligence and Law.

[10] Prakken, H. (2017) On the Problem of Making Autonomous Vehicles Conform to Traffic Law. Artificial Intelligence and Law, 25 (3).

[11] Schellekens, M. (2015) Self-driving Cars and the Chilling Effect of Liability law. Computer Law \& Security Review, 31 (4).

[12] Schellekens, M. (2018) No-fault Compensation Schemes for Self-driving Vehicles. Law, Innovation and Technology, 10 (2). 